\title{
Perancangan Aplikasi Mobile Katalog Furniture Menggunakan Teknologi Augmented Reality
}

\author{
Yudhi Widya Arthana Rustam \\ Program Studi Sistem Informasi \\ STMIK Indonesia Mandiri, Jln. Belitung no.7 Bandung \\ Email: yudhie@stmik-im.ac.id
}

\begin{abstract}
ABSTRAK
Furniture adalah istilah yang digunakan untuk perabotan rumah tangga yang berfungsi sebagai tempat penyimpanan, tempat duduk ataupun hanya sebagai hiasan untuk memperindah sebuah ruangan. Furniture memiliki banyak manfaat, hal tersebut membuat semakin banyaknya orang-orang untuk membeli furniture. Untuk mempermudah dan membuat konsumen lebih tertarik, penjualan furniture dapat memanfaatkan teknologi Augmented Reality. Augmented reality (AR) merupakan sebuah teknik yang menggabungkan objek virtual atau benda maya dua dimensi (2D) maupun tiga dimensi (3D) ke dalam suatu lingkungan yang nyata secara real-time.

Dengan memanfaatkan Augmented Reality menjadi sebuah aplikasi katalog furniture, dapat mempermudah dan membantu baik pelaku bisnis maupun konsumen. Aplikasi ini akan mendeteksi sebuah marker (penanda) yang telah disediakan, setelah marker terdeteksi model 3D furniture akan muncul pada permukaan marker seolah-olah model 3d furniture tersebut nyata dan konsumen sebagi user (pengguna) aplikasi dapat melakukan kontrol terhadap mode 3D tersebut seperti menggeser posisi, mengubah ukuran, memutar rotasi dan mengganti warna. Metodologi yang digunakan dalam perancangan aplikasi ini menggunakan System Development Life Cyrcle (SDLC) dengan model Luther (1944).

Aplikasi Augmented Reality dibuat dengan dengan bantuan Vuforia SDK untuk membuat marker dan Unity sebagai engine atau sistem pembuat aplikasi. Dengan adanya aplikasi ini diharapkan menjadi sebuah media promosi baru yang akan terjadi peningkatan pembeli terhadap furniture yang ditawarkan oleh toko mebel.
\end{abstract}

Kata Kunci : Augmented Reality, Android, furniture, Vuforia, Unity, katalog.

\section{ABSTRACT}

Furniture is a term used for household furniture that functions as a storage area, a seat or just as a decoration to beautify a room. Furniture has many benefits, it makes more and more people to buy furniture. To make it easier and make consumers more interested, furniture sales can take advantage of Augmented Reality technology. Augmented reality $(A R)$ is a technique that combines virtual objects or virtual objects in two dimensions $(2 D)$ and three dimensions $(3 D)$ into a real environment in real time.

By utilizing Augmented Reality into a furniture catalog application, it can simplify and help both business people and consumers. This application will detect a marker that has been provided, after the marker is detected the 3D furniture model will appear on the surface of the marker as if the 3d furniture model is real and the consumer as the user of the application can control the $3 D$ mode such as shifting the position, resize, 
rotate rotation and change color. The methodology used in designing this application uses the System Development Life Cyrcle (SDLC) with the Luther model (1944).

Augmented Reality applications are made with the help of the Vuforia SDK to create markers and Unity as an engine or application development system. With this application, it is expected to be a new promotional media that will increase buyers of furniture offered by furniture stores.

Keywords: Augmented Reality, Android, furniture, Vuforia, Unity, catalog

\section{PENDAHULUAN}

Rumah merupakan salah satu kebutuhan premier manusia yang digunakan sebagai tempat tinggal. Rumah membutuhkan barang furniture sebagai pelengkap aktifitas penghuni rumah dan sebagai hiasan untuk memperindah suatu ruangan yang ada didalam rumah. Furniture adalah istilah yang digunakan untuk perabotan rumah tangga yang berfungsi sebagai tempat penyimpanan barang, tempat duduk, tempat mengerjakan sesuatu dalam bentuk meja atau tempat menaruh barang di permukaannya. Dengan furniture, anda dapat mengekspresikan interior rumah yang sesuai dengan gaya dan kepribadian, karena furniture adalah modal utama dalam penentuan interior rumah.

Seiring dengan banyaknya usaha penjualan furniture sekarang ini, membuat semakin ketatnya persaingan yang ada di pasar. Semakin ketatnya persaingan memaksa para pelaku bisnis untuk memikirkan cara agar produk mereka lebih dikenal oleh masyarakat, diantaranya dengan pengenalan langsung kepada konsumen, dengan mengikuti acara pameran mabel dan interior, menggunakan iklan sebagai media pengenalan. Untuk penawaran langsung kepada konsumen pemilik perusahaan melakukan strategi membawa katalog dan brosur.

Katalog adalah sebuah buku yang bisa berisi dengan gambar. Katalog biasanya berisi informasi sebuah produk, seperti gambar, harga, ukuran, dan lain-lain. Dengan menggunakan katalog, konsumen dapat melihat-lihat apa saja produk yang dijual dan dapat juga dapat meningkatkan konsumen yang berbelanja. Cara penjualan yang dilakukan dengan membawa katalog atau brosur dan hanya memperlihatkan contoh foto-foto furniture, terkadang terjadi ketidakcocokan bayangan pembeli saat melihat foto dari katalog dan saat melihat barang aslinya di toko. Untuk melihat produk pembeli tidak puas hanya dengan melihat melalui katalog atau brosur, maka para pembeli tetap harus datang ke toko langsung untuk melihat bentuk aslinya. Dengan datang ke toko membuat pembeli beranggapan bahwa cara yang dilakukan tidak strategis karena tipe 
pembeli saat ini lebih menyukai cara yang mudah sehingga lebih menghemat waktu dan biaya untuk melihat barang yang ditawarkan.

Perkembangan teknologi saat ini banyak yang dapat dimanfaatkan untuk berbagai hal, salah satunya dalam perkembangan bisnis. Sehubungan dengan masalah yang terjadi pada saat ini pelaku bisnis furniture dapat memanfaatkan media yang menyediakan barang furniture yang mudah dibawa kapan pun dan dimana pun, dalam bentuk virtual object. Virtual object dapat merealisasikan barang yang sudah jadi atau barang yang belum selesai pembuatannya menjadi nyata dalam wujud visualisasi $3 D$ object. Visualisasi $3 D$ object sebagai media untuk menyampaikan informasi produk dan pengalaman virtual memberikan nilai lebih yang signifikan untuk para pembeli furniture. Salah satu teknologi yang bisa digunakan dalam pengembangan visualisasi $3 D$ object adalah Augmented Reality, yaitu teknologi yang dapat memadukan antara dunia maya dengan dunia nyata. Dengan menggunakan teknologi Augmented Reality, pelaku bisnis dapat lebih mudah dan terbantu untuk menawarkan furniture kepada pembeli juga akan membuat pembeli terhibur dan memperoleh informasi konten yang bermafaat.

Fokus utama dari penelitian ini adalah untuk menyediakan suatu desain model dan prototype media penjualan dimana pengguna dapat menggunakan Augmented Reality untuk memperlihatkan barang furniture yang muncul dari katalog yang telah disediakan. Dengan menggunakan model tersebut pembeli memperoleh informasi yang lebih lengkap dan dapat melihat secara detail mengenai furniture yang ditawarkan. Penjual pun terbantu dalam melakukan proses pemasaran dan dapat menarik lebih banyak pembeli.

\section{Identifikasi Masalah}

Berdasarkan latar belakang penelitian yang telah dikemukakan sebelumnya, permasalahan yang dihadapi oleh pelaku bisnis furniture adalah persaingan bisnis yang semakin ketat dan perubahan prilaku konsumen dalam kebiasaan membeli suatu barang.

Merujuk pada latar belakang yang sudah dijelaskan diatas, berikut adalah rumusan masalah dari penelitian ini:

1. Media apa yang digunakan untuk menyediakan sebuah promosi baru dari produk furniture agar terlihat lebih menarik dimata konsumen? 
2. Cara apa yang dilakukan pelaku bisnis untuk menyesuaikan perubahan prilaku konsumen dalam kebiasaan membeli suatu barang?

3. Inovasi apa yang digunakan dalam proses pemasaran furniture ini?

\section{Tujuan Penelitian}

Berdasarkan dari identifikasi masalah yang ada maka tujuan dibuatnya penelitian ini adalah:

1. Membuat aplikasi yang bisa menampilkan visualisasi tiga dimensi (3D) dari sebuah produk furniture yang dipadukan dengan katalog furniture yang sudah disediakan untuk dijadikan sebagai media promosi baru agar lebih menarik dimata konsumen.

2. Dengan menyediakan aplikasi ini pelaku bisnis dapat menarik minat pembeli dan dapat mengenalkan produknya.

3. Membuat perbedaan pemasaran dalam persaingan penjualan furniture.

\section{LANDASAN TEORI}

\section{Augmented Reality}

Augmented Reality $(A R)$ atau dalam bahasa Indonesia diterjemahkan menjadi realitas tambahan adalah sebuah teknik yang menggabungkan benda maya dua dimensi maupun tiga dimensi ke dalam sebuah lingkup nyata tiga dimensi lalu memproyeksikan benda-benda maya tersebut dalam waktu nyata (Andre Kurniawan Pamoedji, Maryuni, 2017). Berikut karakteristik yang dimiliki Augmented Reality:

1. Menggabungkan lingkungan nyata dan virtual.

2. Berjalan secara interaktif dalam waktu nyata.

3. Integrasi dalam tiga dimensi $(3 D)$.

Augmented Reality juga merupakan kombinasi dunia maya (virtual) dan dunia nyata (real) yang dibuat oleh komputer. Objek virtual dapat berupa teks, animasi, model $3 D$ atau video yang digabungkan dengan lingkungan sebenarnya sehingga pengguna merasakan objek virtual berada dalam lingkungannya. Augmented Reality adalah cara baru dan menyenangkan dimana manusia dapat berinteraksi dengan komputer, karena dapat mebawa objek virtual ke lingkungan pengguna dan memberikan pengalaman visualisasi yang alami dan menyenangkan. 
Augmented Reality merupakan variasi dari Virtual Environments (VE), atau yang lebih dikenal dengan istilah Virtual Reality (VR). Teknologi Virtual Reality membuat pengguna tergabung dalam sebuah lingkungan virtual secara keseluruhan. Ketika tergabung dalam lingkungan tersebut, pengguna tidak bisa melihat lingkungan di sekitarnya. Sebaliknya, Virtual Reality memungkinkan pengguna untuk melihat lingkungan nyata, dengan objek virtual yang ditambahkan atau tergabung dengan lingkungan nyata. Tidak seperti Virtual Reality yang sepenuhnya menggantikan lingkungan nyata, Augmented Reality sekedar menambahkan atau melengkapi lingkungan nyata.

Dengan bantuan teknologi Augmented Reality, lingkungan nyata di sekitar kita akan dapat berinteraksi dalam bentuk digital (virtual). Informasi-informasi tentang obyek dan lingkungan disekitar kita dapat ditambahkan ke dalam sistem Augmented Reality yang kemudian informasi tersebut ditampilkan diatas layer dunia nyata secara real-time seolah-olah informasi tersebut adalah nyata.

Augmented Reality merupakan salah satu cabang di bidang teknologi yang belum terlalu lama, namun memiliki perkembangan yang sangat cepat. Perkembangan Augmented Reality pada industri mobile phone juga mempunyai perkembangan yang paling cepat.

\section{Sejarah Augmented Reality}

Sejarah tentang Augmented Reality dimulai dari tahun 1957-1962, ketika seorang penemu yang bernama Morton Heilig, seorang sinematografer, menciptakan dan mempatenkan sebuah simulator yang disebut Sensorama dengan visual, getaran dan bau. Pada tahun 1966, Ivan Sutherland menemukan head-mounted display yang dia klaim adalah jendela ke dunia virtual. Tahun 1975 seorang ilmuwan bernama Myron Krueger menemukan Videoplace yang memungkinkan pengguna, dapat berinteraksi dengan objek virtual untuk pertama kalinya. Tahun 1989, Jaron Lanier memeperkenalkan Virtual Reality dan menciptakan bisnis komersial pertama kali di dunia maya, Tahun 1992 mengembangkan Augmented Reality untuk melakukan perbaikan pada pesawat boeing, dan pada tahun yang sama, LB Rosenberg mengembangkan salah satu fungsi sistem Augmented Reality, yang disebut Virtual Fixtures, yang digunakan di Angkatan Udara AS Armstrong Labs, dan menunjukan manfaatnya pada manusia, dan pada tahun 1992 juga, Steven Feiner, Blair Maclntyre 
dan dorée Seligmann, memperkenalkan untuk pertama kalinya Major Paper untuk perkembangan Prototype Augmented Reality (Ramadar, 2014).

Pada tahun 1999, Hirokazu Kato, mengembangkan ArToolkit di HITLab dan didemonstrasikan di SIGGRAPH, pada tahun 2000, Bruce. H. Thomas, mengembangkan ARQuake, sebuah Mobile Game Augmented Reality yang ditunjukan di International Symposium on Wearable Computers (Ramadar, 2014).

Pada tahun 2008, Wikitude Augmented Reality Travel Guide, memperkenalkan Android G1 Telephone yang berteknologi Augmented Reality. Tahun 2009, Saqoosha memperkenalkan FLARToolkit yang merupakan perkembangan dari ArToolkit. FLARToolkit memungkinkan kita memasang teknologi AR di sebuah website, karena output yang dihasilkan FLARToolkit berbentuk Flash. Ditahun yang sama, Wikitude Drive 9 meluncurkan sistem navigasi berteknologi Augmented Reality di Platform Android. Tahun 2010, Acrossair menggunakan teknologi Augmented Reality pada iPhone 3Gs (Sutoyo et al., 2009).

\section{Model Luther}

Luther menggunakan istilah "authoring” untuk mendefinisikan pengembangan perangkat lunak multimedia. Luther mendefinisikan langkah-langkah pengembangan perangkat lunak multimedia dengan 6 tahap, dimana setiap tahapannya tidak harus berurutan, tetapi dapat dikerjakan secara parallel dengan tahapan perencanaan (concept dan design) harus dimulai dulu (Iwan Binanto, 2015).

Metode Luther mendefinisikan langkah-langkah pengembangan perangkat lunak multimedia dengan 6 tahapan, yaitu Concept, Design, Collecting Content Material, Assembly, Testing dan Distribution. Dimana setiap tahapannya tidak harus berurutan, tetapi dapat dikerjakan secara parallel dengan tahapan perencanaan (concept dan design) harus dimulai terlebih dahulu dan tahap terakhir yaitu Distribution. 


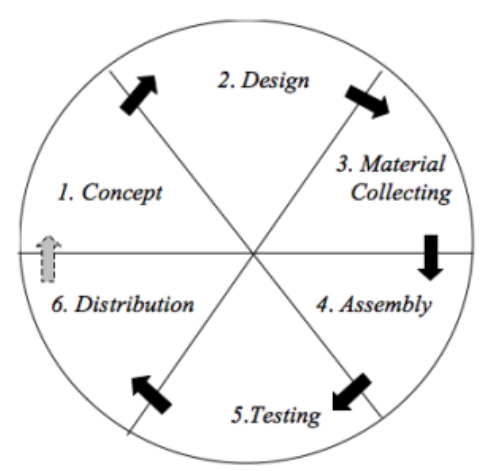

Gambar 1: Model Diagram Luther (H.S. Ariesto, 2013)

1. Concept

Tahap concept (konsep) adalah tahap untuk menentukan tujuan dan siapa pengguna program (identifikasi audience). Selain itu tujuan pengembangan perangkat lunak multimedia di definisikan pada tahapan ini, melingkupi identifikasi pengguna aplikasi, jenis aplikasi (presentasi, interaktif, dst.), tujuan aplikasi (pemberitahuan, hiburan, pengajaran, dst.) dan hal-hal umum. Aturan dasar untuk tahapan design juga sudah diatur dan ditentukan pada tahapan ini, seperti gaya, ukuran aplikasi, platform yang akan digunakan, dan lainnya. Luaran dari tahapan ini semacam dokumen laporan yang merupakan deskripsi naratif dari perangkat lunak multimedia yang diusulkan.

2. Design

Design (perancangan) adalah tahap membuat spesifikasi mengenai arsitektur program, gaya, tampilan dan kebutuhan material/bahan untuk program. Tujuan tahapan ini adalah menentukan secara detil arsitektur, gaya, dan semua material yang akan digunakan pada perangkat lunak multimedia yang akan dikembangkan, tahapan ini diharapkan cukup detail sehingga tahapan-tahapan berikutnya, yaitu content collection dan assembly dapat dilakukan tanpa perlu keputusan-keputusan alternatif lain. Tetapi, tidak semuanya dapat berjalan sesuai yang diharapkan dan sudah biasa ada material baru atau bagian dari aplikasi yang ditambahkan, dihapus, atau diubah di tahapan yang paling akhir pada pengembangan ini. Perangkat lunak authoring akan mulai berguna pada tahapan ini karena system authoring akan mengambil alih tugas pendokumentasian design dan menyimpan informasi dalam suatu bentuk yang dapat dengan mudah berpindah secara 
langsung ke tahapan content collection dan assembly tanpa entry manual. Fitur authoring yang membantu dalam tahapan ini adalah: outlining, storyboarding, flowcharting, dan scripting. Tampilan storyboard atau outline mudah dimengerti untuk presentasi. Pada kasus ini, tampilan flowchart akan lebih baik meskipun akan dipecah-pecah ketika interaktifitas menjadi lebih kompleks karena akan didapat banyak garis-garis yang bersinggungan. Tugas lain pada tahapan ini adalah memutuskan semua content material, termasuk text dan file database, audio, video, dan gambar diam. Tujuannya untuk membuat daftar material yang akan dicari atau dibuat sehingga semuanya akan dapat dikumpulkan pada tahapan berikutnya.

\section{Material Content Collecting}

Dari daftar konten yang sudah dibuat pada tahap design, pengembang harus mengumpulkan konten materialnya. Pekerjaan ini sering dikerjakan secara paralel dengan tahapan assembly. Konten material didapat dari sumber luar atau membuat sendiri sesuai kebutuhan. Sistem authoring akan membantu dengan berbagai cara. Membuat konten material sendiri akan memunculkan beberapa masalah baru, seperti dibutuhkan hardware dan software yang sesuai persyaratan dan keahlian untuk membuat konten material yang dibutuhkan. Misalnya untuk membuat konten audio, dibutuhkan hardware dan software yang dapat merekam dan memanipulasi data audio sehingga sesuai dengan kebutuhannya. Ada beberapa software yang mempermudah pembuatan konten material dengan menyediakan template, tetapi dalam jangka panjang menjadi tidak baik karena hasilnya akan begitu-begitu saja sesuai dengan template yang ada. Konten menjadi tidak unik dan tidak khas.

4. Assembly

Tahap assembly (pembuatan) adalah tahap dimana semua objek atau bahan multimedia dibuat. Pembuatan aplikasi didasarkan pada tahap design. Seluruh material dan yang dibutuhkan digabungkan di tahap ini. Tergantung pada apa yang sudah dikerjakan pada tahap sebelumnya, ada kemungkinan tidak ada pekerjaan pada tahap ini atau justru harus dikerjakan keseluruhan. Ada system authoring yang secara otomatis membangun struktur program dari flowchart yang sudah diberikan dan pengembang hanya memasukkan konten material ke tempat 
yang sudah disediakan. Ada aplikasi yang mengharuskan pekerjaan yang terperinci dan pemrograman tingkat lanjut yang membutuhkan orang yang ahli dibidang tersebut. Penyederhanaan hal-hal kompleks dalam pengembangan dapat diatasi dengan pembuatan serangkaian modul-modul sehingga hal-hal yang mirip dapat diatasi dengan modul-modul tersebut. Tahapan ini juga menyarankan pengembangan berdasar pada modul-modul yang lebih kecil. Modul memberi keuntungan reusable, artinya dapat digunakan berulang kali sehingga tidak perlu memperbesar aplikasi yang sedang dibangun.

5. Testing

Ketika aplikasi sudah dibangun dan konten material sudah masuk ke dalamnya, aplikasi harus di tes untuk meyakinkan bahwa semuanya berjalan sesuai dengan keinginan. Sebenarnya, hal ini sudah dilakukan juga ketika sedang pada tahap assembly dan sangat penting ketika system authoring mengijinkan pengembang untuk melihat dan memeriksa pekerjaan yang sedang berlangsung. Untungnya, kebanyakan sistem mempunyai fitur untuk testing dan mengijinkan pengembang menjalankan aplikasinya untuk perbagian atau secara menyeluruh dan melaporkan adanya kesalahan yang terjadi ketika sedang dijalankan. Proses ini sering disebut sebagai debugging. Hal yang lebih penting sebenarnya adalah testing untuk melihat apakah aplikasi yang dibangun berjalan dengan baik di lingkungan yang sebenarnya, dalam hal ini kompatibilitas hardware atau software nya. Biasanya, aplikasi yang dibangun akan digunakan di lingkungan yang berbeda dengan ketika aplikasi tersebut dibangun. Jadi aplikasi harus di tes di lingkungan yang sebenarnya untuk memastikan semuanya dapat berjalan dengan baik. Selain itu, juga diperlukan testing kepada pengguna untuk meyakinkan bahwa pengguna dapat menggunakan aplikasi dengan baik.

\section{Distribution}

Pada tahap ini, aplikasi akan disimpan dalam suatu media penyimpanan. Jika media penyimpanan tidak cukup untuk menampung aplikasinya, kompresi terhadap aplikasi tersebut akan dilakukan. Tahap ini juga dapat disebut tahap evaluasi untuk pengembangan produk yang sudah jadi supaya menjadi lebih baik. Hasil evaluasi ini dapat digunakan sebagai masukan untuk tahap concept pada produk selanjutnya. Cara pendistribusian aplikasi yang sudah sepenuhnya siap 
digunakan harus disiapkan dan disesuaikan dengan lingkungan yang sebenarnya. Pengembang sebaiknya mempunyai beberapa alternative untuk pendistribusian ini, misalnya dengan CDROM/DVDROM, flashdisk, atau internet. Hal ini juga terkait dengan jumlah dan besarnya file yang ada maupun penataan file yang diperlukan oleh aplikasi.

\section{Unified Modeling Language}

UML singkatan dari Unified Modeling Language yang berarti bahasa pemodelan standar. Chonoles dalam Muslihudin (2016) mengatakan sebagai bahasa, berarti $U M L$ memiliki sintaks dan semantik. Ketika kita membuat model menggunakan $U M L$ ada aturan-aturan yang harus diikuti. Bagaimana elemen pada model-model yang kita buat berhubungan satu dengan yang lainnya harus mengikuti standar yang ada. $U M L$ bukan hanya sekedar diagram, tetapi juga menceritakan konteksnya (Oktafianto \& Muslihudin, 2016).

UML (Unified Modeling Language) adalah salah suatu standar bahasa yang banyak digunakan di dunia industri untuk mendefinisikan requirement, membuat analisis dan design, serta menggambarkan arsitektur dalam pemrograman berorientasi objek.

$U M L$ menyediakan serangkaian gambar dan diagram yang sangat baik. Beberapa diagram memfokuskan diri pada ketangguhan teori object oriented dan sebagian lagi memfokuskan pada detail rancangan dan konstruksi (A.S \& Shalahuddin, 2016). Semua dimaksudkan sebagai sarana komunikasi antar team programmer maupun dengan pengguna. UML dideskripsikan oleh beberapa diagram, yaitu sebagai berikut:

\section{Use Case Diagram}

Use case merupakan pemodelan untuk kelakuan (behavior) sistem informasi yang akan dibuat. Use case mendeskripsikan sebuah interaksi antara satu atau lebih aktor dengan sistem. Adapun simbol-simbol yang digunakan dalam use case adalah sebagai berikut: 
Tabel 1. Simbol-simbol Use Case Diagram

\begin{tabular}{|c|c|c|}
\hline Sim & Nama & Deskripsi \\
\hline & Actor & $\begin{array}{l}\text { Orang, proses, atau sistem lain } \\
\text { yang berinteraksi dengan sistem } \\
\text { informasi yang akan dibuat di luar } \\
\text { sistem informasi yang akan dibuat } \\
\text { itu sendiri. }\end{array}$ \\
\hline & Use case & $\begin{array}{l}\text { Fungsionalitas yang disediakan } \\
\text { sistem sebagai unit-unit yang saling } \\
\text { bertukar pesan antar unit atau aktor. }\end{array}$ \\
\hline & Association & $\begin{array}{l}\text { Komunikasi antara aktor dan use } \\
\text { case yang berpartisipasi pada use } \\
\text { case atau use case memiliki } \\
\text { interaksi dengan aktor. }\end{array}$ \\
\hline$<<$ exte & Extend & $\begin{array}{l}\text { Relasi use case tambahan ke } \\
\text { sebuah use case yang } \\
\text { ditambahkan dapat berdiri sendiri } \\
\text { walau tanpa use case tambahan itu. }\end{array}$ \\
\hline & Generalization & $\begin{array}{l}\text { Hubungan generalisasi dan } \\
\text { spesialisasi (umum-khusus) antara } \\
\text { dua buah use case dimana fungai } \\
\text { yang satu adalah fungsi yang lebih } \\
\text { umum dari lainnya. }\end{array}$ \\
\hline$<<$ includ & include & $\begin{array}{l}\text { Relasi use case tambahan ke } \\
\text { sebuah use case dimana use case } \\
\text { yang ditambahkan memerlukan use } \\
\text { case ini untuk menjalankan } \\
\text { fungsinya atau sebagai syarat } \\
\text { dijalankan use case ini. }\end{array}$ \\
\hline
\end{tabular}

\section{Activity Diagram}

Activity diagram menggambarkan workflow (aliran kerja) atau aktivitas dari sebuah sistem atau proses bisnis atau menu yang ada pada perangkat lunak. Yang perlu diperhatikan disini adalah bahwa diagram aktivitas menggambarkan aktivitas sistem bukan apa yang dilakukan aktor, jadi aktivitas yang dapat dilakukan oleh sistem. Adapun simbol-simbol yang digunakan dalam activity diagram adalah sebagai berikut: 
Tabel 2. Simbol-simbol activity diagram

\begin{tabular}{|c|c|c|}
\hline Simbol & Nama & Deskripsi \\
\hline & Status awal & $\begin{array}{l}\text { Status awal aktivitas sistem, sebuah } \\
\text { diagram aktivitas memiliki sebuah } \\
\text { status awal }\end{array}$ \\
\hline & Aktivitas & $\begin{array}{l}\text { Aktivitas yang dilakukan sistem, } \\
\text { biasanya diawali dengan kata kerja. }\end{array}$ \\
\hline & Decision & $\begin{array}{l}\text { Asosiasi percabangan dimana jika } \\
\text { ada pilihan aktivitas lebih dari satu. }\end{array}$ \\
\hline & Join & $\begin{array}{l}\text { Asosiasi penggabungan dimana lebih } \\
\text { dari satu aktivitas digabungkan } \\
\text { menjadi satu. }\end{array}$ \\
\hline & Status akhir & $\begin{array}{l}\text { Status akhir yang dilakukan sebuah } \\
\text { sistem, sebuah diagram aktivitas } \\
\text { memiliki sebuah status akhir. }\end{array}$ \\
\hline & Swimlane & $\begin{array}{l}\text { Memisahkan organisasi bisnis yang } \\
\text { bertanggung jawab } \\
\text { aktivitas yang terjadi. }\end{array}$ \\
\hline
\end{tabular}

\section{Class Diagram}

Class diagram menggambarkan struktur sistem dari segi pendefinisian kelas-kelas yang akan dibuat untuk membangun sistem. Diagram kelas dibuat agar pembuat program atau programmer membuat kelas-kelas sesuai rancangan di dalam diagram kelas agar antara dokumentasi perancangan dan perangkat lunak sinkron. Adapun simbol-simbol yang digunakan dalam class diagram adalah sebagai berikut:

Tabel 3. Simbol class diagram

\begin{tabular}{ccl}
\hline Gambar & Nama & \multicolumn{1}{c}{ Deskripsi } \\
\hline & Class & Kelas pada struktur \\
\hline & Anterface & $\begin{array}{l}\text { Sama dengan konsep interface } \\
\text { dalam pemrograman berorientasi } \\
\text { objek. }\end{array}$ \\
\hline & Association & $\begin{array}{l}\text { Relasi antar kelas dengan makna } \\
\text { umum, asosiasi biasanya juga } \\
\text { disertai dengan multiplicity. }\end{array}$ \\
\hline & Directed & Relasi antar kelas dengan makna \\
\hline
\end{tabular}




\begin{tabular}{lll}
\hline & association & $\begin{array}{l}\text { kelas yang satu digunakan oleh } \\
\text { kelas yang lain }\end{array}$ \\
\hline & Generalization & $\begin{array}{l}\text { Relasi antar kelas dengan makna } \\
\text { generalisasi-spesialisasi (umum } \\
\text { khusus) }\end{array}$ \\
\hline & Dependency & $\begin{array}{l}\text { Relasi antar kelas dengan makna } \\
\text { kebergantungan antar kelas }\end{array}$ \\
\hline & Aggregation & $\begin{array}{l}\text { Relasi antar kelas dengan makna } \\
\text { semua bagian (whole-part) }\end{array}$ \\
\hline
\end{tabular}

\section{Entity Relationship Diagram (ERD)}

Entity relationship diagram (ERD) merupakan tools yang digunakan untuk memodelkan struktur data dengan menggambarkan entitas dan hubungan antar enititas (relationship) secara abstrak (konseptual) (Mulyani, 2016). 3 (tiga) fungsi utama ERD yaitu:

1. Sebagai alat untuk memodelkan hasil dari analisis data.

2. Sebagai alat untuk memodelkan data konseptual (lojikal).

3. Sebagai alat untuk memodelkan objek-objek dalam suatu sistem (dasar dari object diagram/class diagram).

Tabel 4. Notasi Entity Relationship Diagram

\begin{tabular}{|c|c|c|c|}
\hline No & Notasi & Nama & Pengertian \\
\hline 1 & & Entity & $\begin{array}{l}\text { Suatu objek yang utuh dari } \\
\text { independen terhadap suatu objek } \\
\text { lain dalam lingkup masalah } \\
\text { yang ditinjau (memiliki fungsi } \\
\text { relevan terhadap sistem) }\end{array}$ \\
\hline 2 & & Week entity & $\begin{array}{llr}\text { Suatu entity } & \text { set } & \text { yang } \\
\text { keberadaannya } & \text { lemah } & \text { (tidak } \\
\text { diperlukan jika } & \text { entity } & \text { kuatnya } \\
\text { tidak ada) } & & \end{array}$ \\
\hline 3 & & Attribute & $\begin{array}{l}\text { Pendeskripsian karakteristik dari } \\
\text { entitas }\end{array}$ \\
\hline 4 & & Relationship & $\begin{array}{l}\text { Deskripsi hubungan antar enity } \\
\text { dari kategori yang berbeda atau } \\
\text { sama }\end{array}$ \\
\hline
\end{tabular}




\section{PEMBAHASAN}

\section{Concept}

Tahap concept merupakan tahapan untuk menentukan tujuan dan siapa pengguna program. Untuk menentukan tujuan dan siapa pengguna program maka dilakukan analisis sistem. Analisis sistem merupakan penguraian dari suatu sistem untuk mengidentifikasikan masalah-masalah dan hambatan-hambatan yang terjadi pada sistem yang akan dibuat atau yang sedang berjalan, sehingga dapat diusulkan kebutuhankebutuhan uantuk memperbaikinya. Tahap analisis sistem adalah tahapan dasar sebelum perancangan untuk memperbaiki sebuah sistem, sehingga dari hasil analisis tersebut dapat dirancang sebuah sistem baru atau diperbaiki sebuah sistem yang lebih efektif dan efisien.

\section{A. Analisis Sistem yang Sedang Berjalan}

Analisis sistem adalah tahapan yang memberi gambaran tentang sistem yang sedang berjalan sekarang. Analisis ini bertujuan untuk memberi gambaran yang lebih detail mengenai cara kerja dari sistem yang sedang berjalan. Adapun analisis prosedur pada proses media yang sedang berjalan adalah seperti pada gambar 2 .

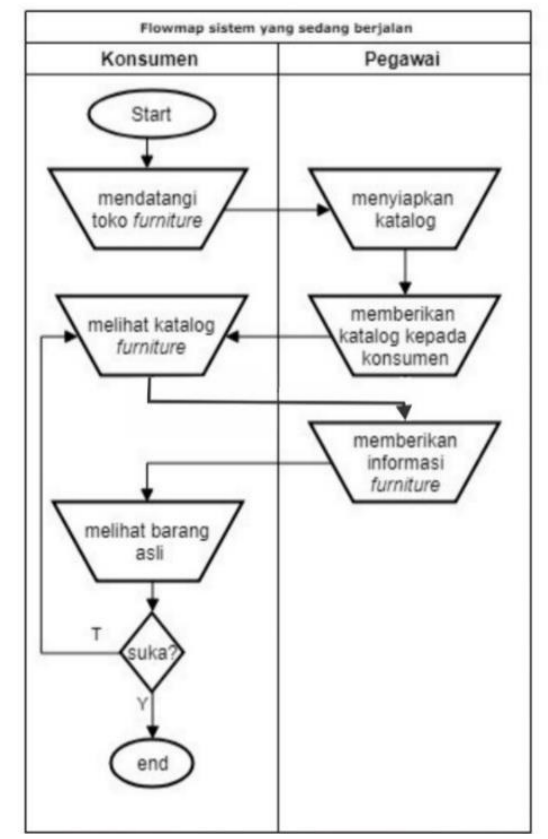

Gambar 2. Flowmap sistem yang sedang berjalan 
1. Konsumen mendatangi sebuah toko Furniture.

2. Konsumen mendapatkan informasi dari media yang digunakan oleh toko furniture tersebut, diantaranya:

a. Pegawai akan menyampaikan dan menjelaskan informasi kepada konsumen mengenai detail-detail dari furniture yang ada di toko tersebut.

b. Katalog Furniture, menampilkan informasi berupa gambar furniture kepada calon pembeli.

c. Melihat furniture secara langsung jika stok barang masih ada.

Dari gambaran prosedur diatas terlihat beberapa media yang saat ini digunakan sebagai media untuk memperoleh informasi mengenai detail dari furniture yang ada di toko tersebut masih memiliki beberapa kekurangan, diantaranya informasi yang diberikan oleh penjaga toko kepada calon pembeli kurang jelas dikarenakan kurangnya pengetahuan calon pembeli mengenai detail furniture tersebut, serta terbatasnya informasi yang ada dalam katalog furniture.

\section{B. Analisis Sistem yang Akan Dibangun}

Sistem yang akan dibangun adalah sebuah aplikasi berbasis android yang menggunakan teknologi Augmented Reality. Teknologi Augmented Reality dipilih karena memiliki beberapa kelebihan, salah satunya teknologi ini dapat menampilkan objek tiga dimensi (3D) secara realtime, sehingga dapat menjadi solusi dari permasalahan yang ada dan dapat dijadikan sebuah media pomosi baru dari produk furniture agar terlihat lebih menarik dimata konsumen. Untuk dapat menampilkan objek Augmented Reality digunakan metode marker based dengan teknik object tracking. Dalam proses object tracking digunakan bantuan dari Library Vuforia SDK. Library Vuforia SDK dipilih karena library ini memiliki kelebihan komputasinya yang sangat 
cepat dalam mendeteksi objek, karena hanya bergantung pada jumlah feature yang ada dalam sebuah objek target.

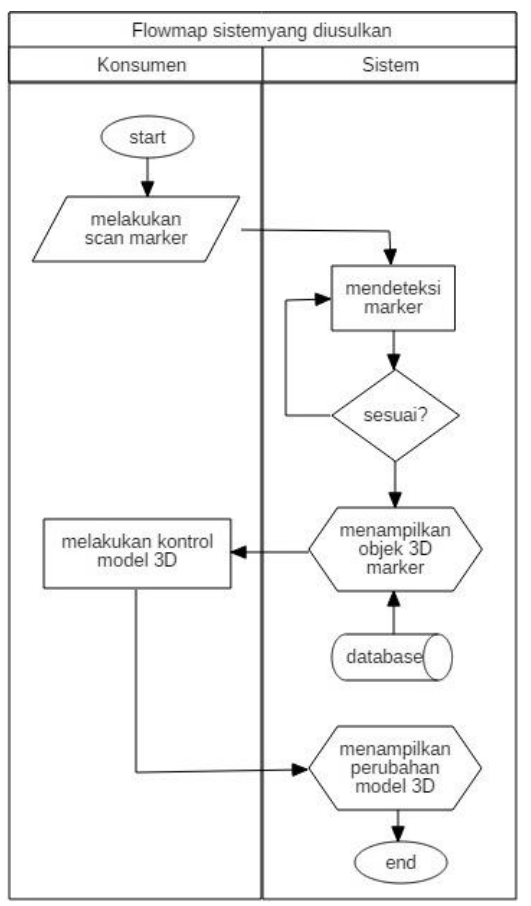

Gambar 2. Flowmap Sistem yang akan Dibangun

1. Pengguna yang akan menggunakan aplikasi adalah konsumen.

2. Pengguna menggunakan smartphone yang telah dilengkapi dengan aplikasi Augmented Reality untuk melakukan scan pada marker yang telah disediakan didalam katalog furniture yang akan dicocokan datanya kedalam aplikasi Augmented Reality tersebut.

3. Setelah data marker cocok maka akan muncul objek tiga dimensi (3D) furniture.

\section{Analisis Pengguna}

Analisis pengguna menjelaskan siapa yang akan menggunakan atau menjalankan aplikasi agar dapat berjalan secara optimal dan sesuai dengan yang diharapkan. Pengguna aplikasi ini tidak memiliki batasan usia, namun disarankan pengguna aplikasi ini harus memiliki pemahaman dalam menjalankan smartphone touchscreen. 


\section{Perancangan Sistem Perangkat Lunak}

Perancangan sistem perangkat lunak memiliki tujuan memberikan gambaran dari sistem yang akan dibuat. Penulis menggunakan diagram UML diantaranya use case diagram, activity diagram, dan class diagram.

\section{A. Deskripsi Perancangan Use Case}

Tabel 5. Deskripsi Perancangan Use Case

\begin{tabular}{|c|c|c|}
\hline No & Simbol & Deskripsi \\
\hline 1 & Konsumen & $\begin{array}{l}\text { Pihak yang mempunyai hak akses } \\
\text { untuk melihat informasi furniture } \\
\text { yang ditawarkan dan dapat } \\
\text { melakukan scan marker untuk } \\
\text { melihat model 3D furniture serta } \\
\text { melakukan kontrol terhadap model } \\
\text { 3D tersebut, seperti melakukan } \\
\text { mapping posisi, mengganti warna, } \\
\text { melakukan rotasi dan mengubah } \\
\text { ukuran model 3D. }\end{array}$ \\
\hline 2 & & $\begin{array}{l}\text { Masuk kedalam menu yang akan } \\
\text { menampilkan informasi daftar } \\
\text { furniture yang disediakan }\end{array}$ \\
\hline 3 & & $\begin{array}{l}\text { Menampilkan dan meilih kategori } \\
\text { dari informasi daftar furniture yang } \\
\text { akan dilihat }\end{array}$ \\
\hline 4 & & $\begin{array}{l}\text { Menampilkan model 3D furniture } \\
\text { yang muncul setelah melakukan } \\
\text { identifikasi marker }\end{array}$ \\
\hline 5 & & $\begin{array}{l}\text { Masuk kedalam menu yang akan } \\
\text { melakukan scan marker yang sudah } \\
\text { disediakan untuk menampilkan } \\
\text { model 3D furniture }\end{array}$ \\
\hline 6 & & $\begin{array}{l}\text { Mengubah posisi rotasi dari model } \\
\text { 3D furniture yang muncul }\end{array}$ \\
\hline 7 & & $\begin{array}{l}\text { Mengubah ukuran dari model 3D } \\
\text { furniture yang muncul }\end{array}$ \\
\hline 8 & $\begin{array}{l}\text { posising } \\
\text { posi }\end{array}$ & $\begin{array}{l}\text { Mengubah posisi dari model 3D } \\
\text { furniture yang muncul }\end{array}$ \\
\hline
\end{tabular}




\begin{tabular}{lll}
\hline No & Simbol & \multicolumn{1}{c}{ Deskripsi } \\
\hline $\begin{array}{c}\text { memilih } \\
\text { warna }\end{array}$ & $\begin{array}{l}\text { Mengubah warna dari model 3D } \\
\text { furniture yang muncul }\end{array}$ \\
\hline
\end{tabular}

\section{B. Perancangan Use Case Diagram}

Use case diagram digunakan untuk menggambarkan sistem dari sudut pandang pengguna sistem tersebut.

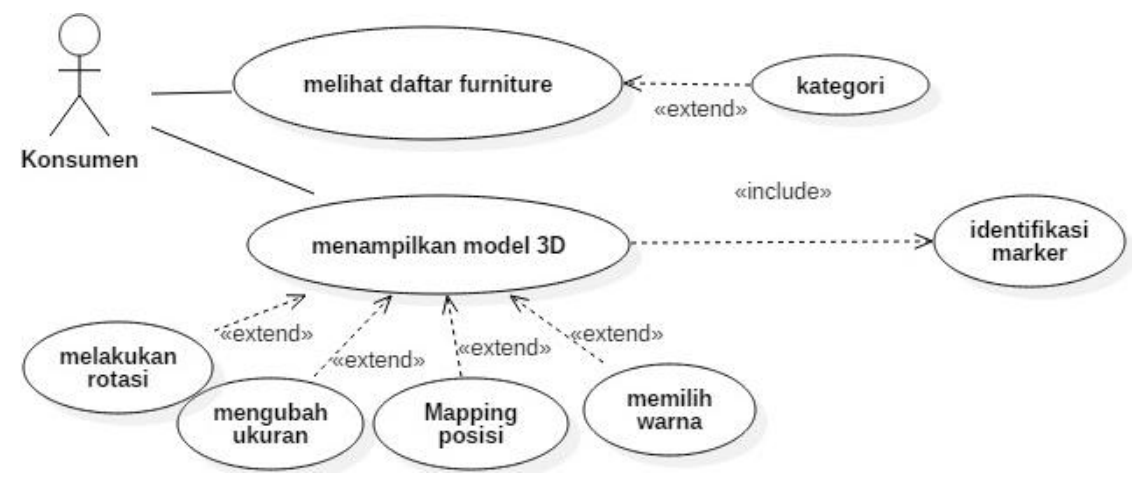

Gambar 2. Use Case Diagram Aplikasi Katalog Furniture

\section{Activity Diagram}

Activity diagram digunakan untuk menggambarkan event-event yang terjadi di dalam use case diagram aplikasi katalog furniture pada gambar 2.

1. Activity diagram daftar furniture

Pada gambar 3, activity diagram tersebut menggambarkan proses untuk masuk ke dalam menu daftar furniture.

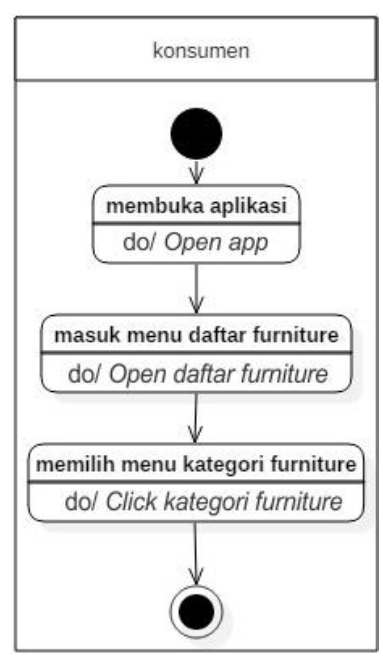

Gambar 3. Activity Diagram Daftar Furniture 
2. Activity Diagram Memilih Kategori

Pada gambar 4, activity diagram tersebut menggambarkan proses untuk melihat informasi dari kategori daftar furniture.

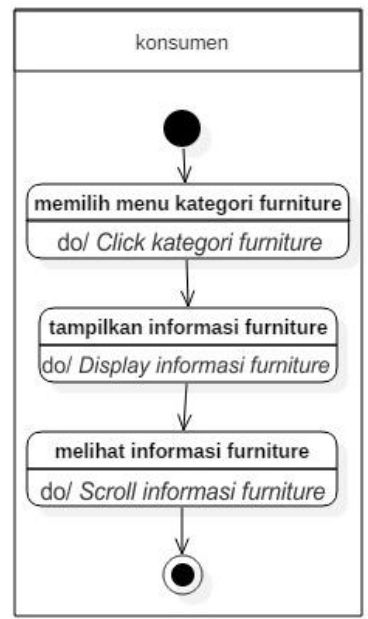

Gambar 4. Activity Diagram Kategori

3. Activity Diagram Identifikasi Marker

Activity diagram pada gambar 5 menggambarkan bagaimana proses identifikasi marker. User harus melakukan scan terlebih dahulu untuk melihat model 3D yang akan muncul.

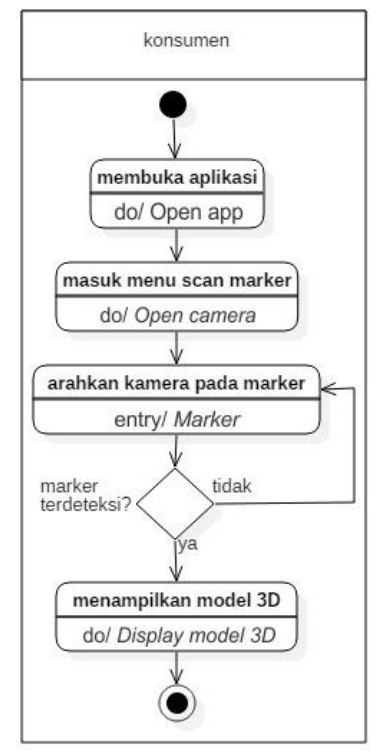

Gambar 5. Activity Diagram Indentifikasi Marker 
4. Activity Diagram Memilih Warna

Activity diagram pada gambar 6 menggambarkan proses dalam mengubah warna pada model 3D.

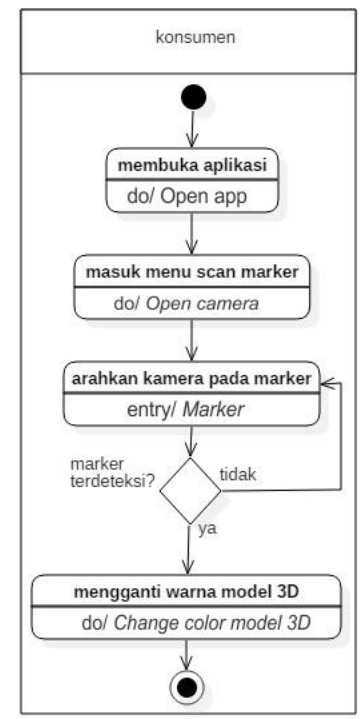

Gambar 6. Activity Diagram Memilih Warna

5. Activity Diagram Mapping Posisi

Activity diagram pada gambar 7 menggambarkan proses dalam mengubah posisi atau mapping dari model 3D.

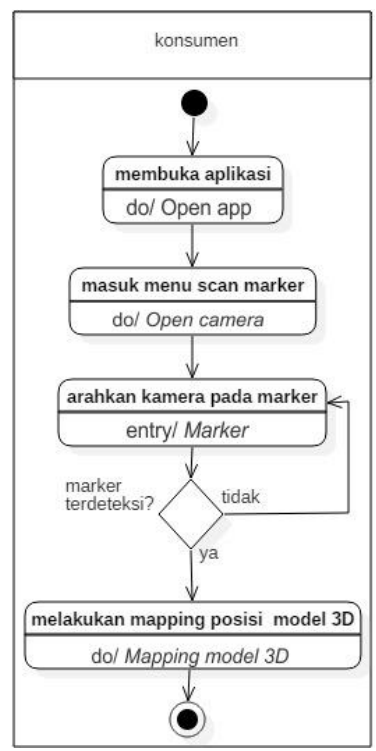

Gambar 7. Activity Diagram Mapping Posisi 
6. Activity Diagram Melakukan Rotasi

Activity diagram pada gambar 8 menggambarkan proses untuk melakukan perubahan rotasi pada model 3D.

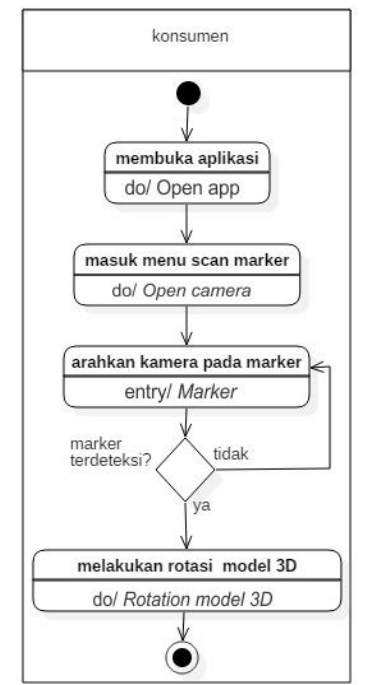

Gambar 8. Activity Diagram Melakukan Rotasi

7. Activity Diagram Mengubah Ukuran

Activity diagram pada gambar 9 menggambarkan mengubah ukuran menampilkan proses yang terjadi saat masuk ke dalam menu scan marker dan mengubah ukuran model 3D.

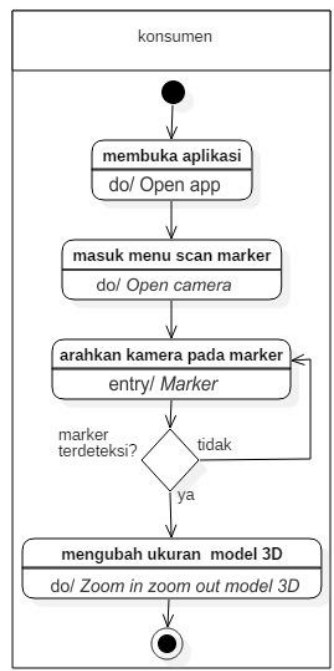

Gambar 9. Activity Diagram Mengubah Ukuran 


\section{Class Diagram}

Class diagram menggambarkan struktur sistem dari segi pendefinisian kelas-kelas yang akan dibuat untuk membangun sistem. Berikut ini gambar 10. yang merupakan class diagram dari aplikasi katalog furniture.

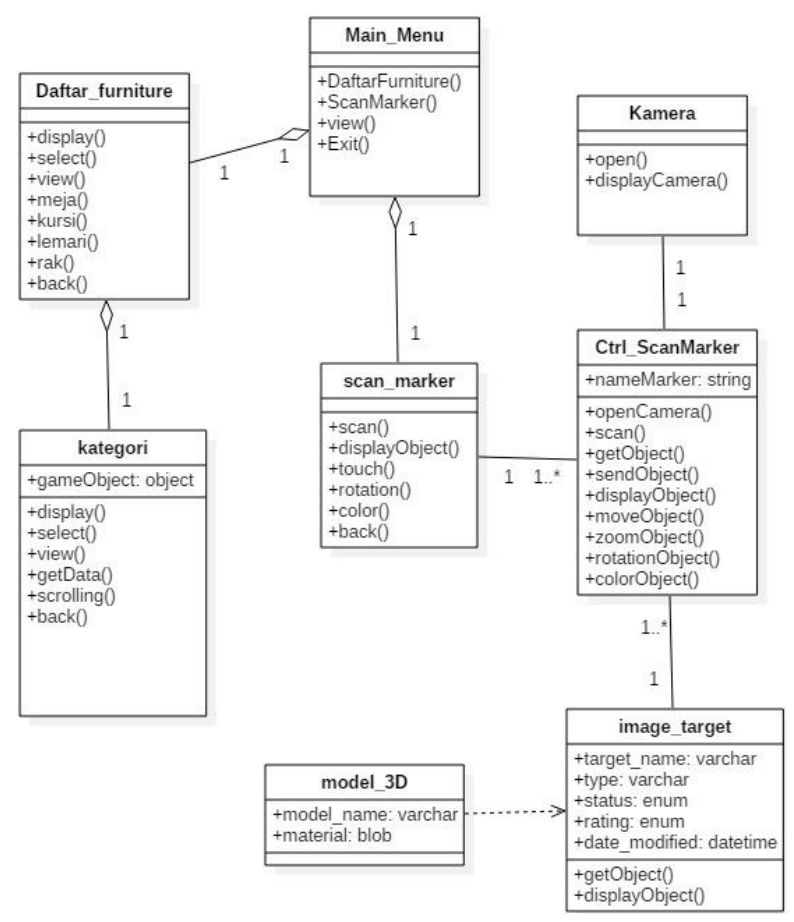

Gambar 10. Class Diagram Katalog Furniture

\section{E. Perancangan Database}

Entity relationship diagram merupakan suatu model yang menjelaskan hubungan antar data dalam database berdasarkan objek-objek dasar data yang mempunyai hubungan antar relasi. Entity relationship diagram memodelkan struktur data dan hubungan antar data, untuk mengambarkannya digunakan beberapa notasi dan simbol.

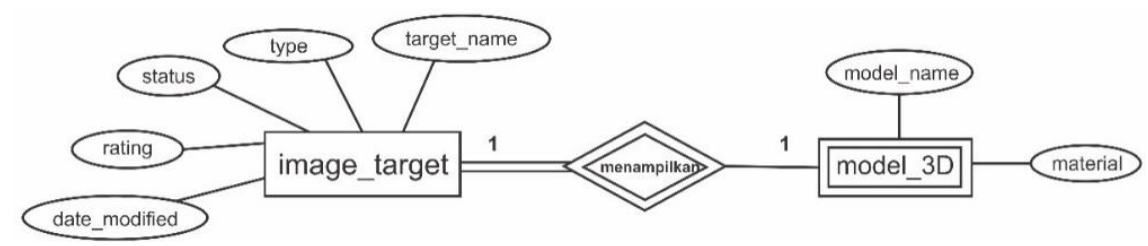

Gambar 11. Entity Relationship Diagram Katalog Furniture

Terdapat dua tabel yang ada pada aplikasi katalog furniture diantaranya tabel image target dan model 3D. Pada tabel 6 menunjukan penjelasan dari isi tabel image target. 
Tabel 6. Tabel Image Target

\begin{tabular}{llll}
\hline Nama & Tipe Data & Ukuran & Key \\
\hline Target_name & Varchar & 30 & Primary-Key \\
\hline Type & Varchar & 20 & - \\
\hline Status & Enum & - & - \\
\hline Rating & Enum & - & - \\
\hline Date_modified & datetime & - & - \\
\hline
\end{tabular}

Tabel model_3D berisikan data mengenai model 3D yang akan muncul pada marker yang telah disiapkan.

Tabel 7. Tabel Model 3D

\begin{tabular}{llll}
\hline Nama & Tipe Data & Ukuran & Key \\
\hline model_name & Varchar & 30 & Primary-Key \\
\hline material & Blob & - & - \\
\hline
\end{tabular}

\section{E. Perancangan Interface}

Setelah melakukan perancangan sistem perangkat lunak, tahap selanjutnya adalah melakukan analisis terhadap perancangan interface yang akan dibangun terdiri dari halaman main menu, halaman daftar furniture, halaman kategori, dan halaman scan marker.

1. Perancangan Interface Main Menu

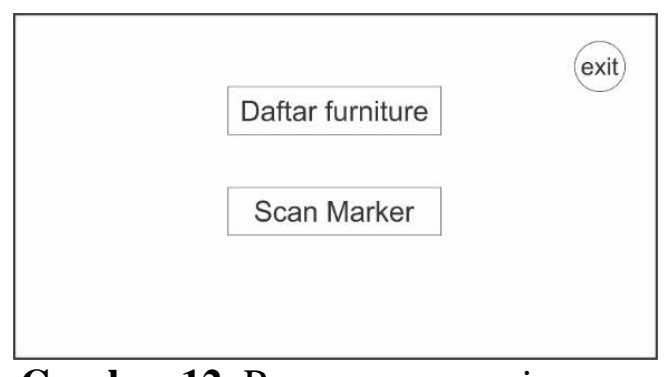

Gambar 12. Perancangan main menu 
2. Perancangan Interface Daftar Furniture

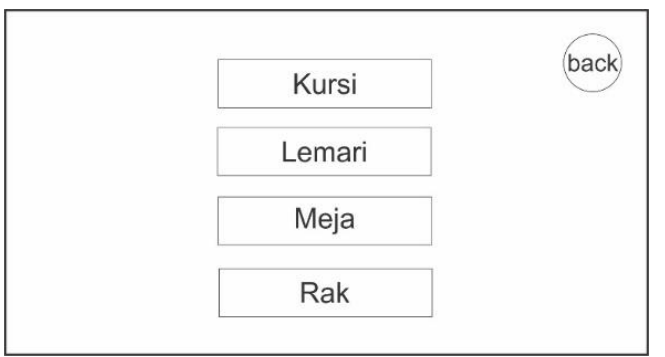

Gambar 13. Perancangan Daftar Furniture

3. Perancangan Interface Kategori

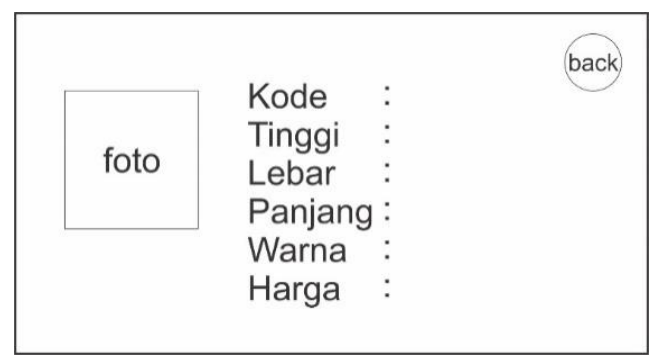

Gambar 14. Perancangan Daftar Kategori

4. Perancangan Interface Scan Marker

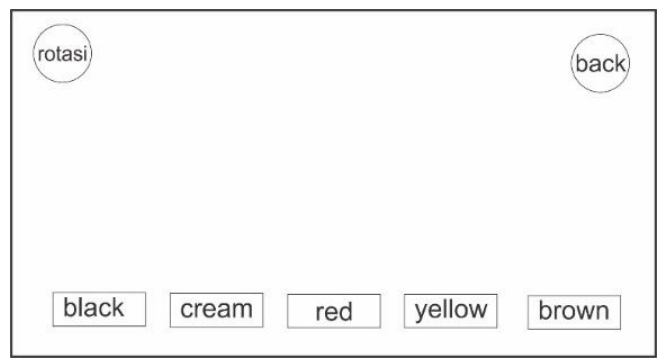

Gambar 15. Perancangan Scan Marker

\section{F. Perancangan Marker}

Marker menjadi sebuah tanda yang akan dibaca oleh sistem untuk menampilkan model 3D. Marker dinilai memiliki mekanisme pengenalan yang sederhana, mestipun terlihat berantakan tetapi marker memiliki informasi penting yang akan dibaca oleh sistem. Desain dari marker yang akan dibuat harus memiliki ciri khas agar dapat dibedakan dengan marker yang lainnya. Pada gambar 16 dapat dilihat contoh perancangan marker yang akan digunakan sebagai permukaan untuk menampilkan 
model 3D. Pada marker tersebut terdapat gambar dari model 3D dan kode model 3D sebagai pembeda dengan marker yang lainnya.

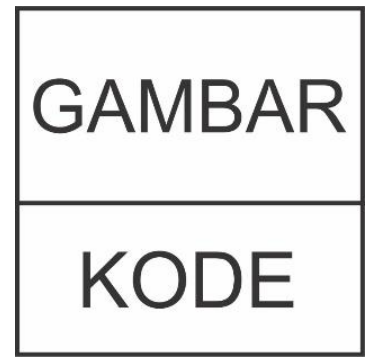

Gambar 16. Perancangan Marker

\section{KESIMPULAN}

Berdasarkan penelitian yang telah dilakukan penulis mengenai perancangan aplikasi android augmented reality katalog furniture, dapat dikemukakan beberapa kesimpulan dari penelitian yang dilakukan sebagai berikut:

1. Adanya aplikasi katalog furnture ini dapat memberikan informasi produk furniture yang ditampilkan pada sebuah desain produk tiga dimensi (3D) yang dapat dijadikan sebagai media promosi baru yang lebih menarik sehingga konsumen menjadi lebih tertarik.

2. Sistem ini dapat memberikan informasi visual secara interaktif dengan cara menampilkan desain produk tiga dimensi (3D) menggunakan teknologi Augmented Reality beserta marker yang berfungsi sebagai penanda untuk memunculkan model 3D yang menyerupai bentuk aslinya serta dapat menarik minta para konsumen dan lebih mudah untuk mengenalkan produk furniture kepada konsumen.

3. Pada aplikasi ini konsumen dapat melakukan kontrol pada model 3D yang muncul, seperti mengatur rotari, melakukan mapping, mengubah ukuran dan 
mengganti warna model 3D sehingga dapat membuat perbedaan dalam persaingan pemasaran furniture.

\section{DAFTAR PUSTAKA}

A.S, R., \& Shalahuddin, M. (2016). Rekayasa Perangkat Lunak Terstruktur dan Berorientasi Objek. Bandung: Informatika. In Jurnal Pilar Nusa Mandiri. Informatika.

Andre Kurniawan Pamoedji, Maryuni, R. S. (2017). Mudah Membuat Augmented Reality dan Virtual Reality dengan Unity 3D. PT. Elex Media Komputindo.

H.S. Ariesto. (2013). Multimedia Interaktif dengan Flash.Yogyakarta. Graha Ilmu.

Iwan Binanto. (2015). Tinjauan Metode Pengembangan Perangkat Lunak Multimedia Yang Sesuai Untuk Mahasiswa Tugas Akhir. Systematic Biology, 63(4), 534-542.

Mulyani, S. (2016). Metode Analisis dan Perancangan Sistem, ISBN: 978-979-19906-22: Vol. Edisi Ke-2. Abdi Sistematika.

Oktafianto, dan M., \& Muslihudin. (2016). Analisis dan Perancangan Sistem Informasi Menggunakan Model Terstruktur dan UML - Muhamad Muslihudin, Oktafianto Google Buku. In Analisis dan Perancangan Sistem Informasi Menggunakan Model Terstruktur dan Uml.

Ramadar, P. (2014). N.S Flartoolkit Flash Augmented Reality Alt Actionscript. AR Online.

Sutoyo, T., Mulyanto, E., Suhartono, V., Nurhayati, \& Wijanarto. (2009). Teori Pengolahan Citra Digital. In Semarang: Andi Offset (Vol. 1, Issue 1). Andi. 